\title{
Fuzzy logic as a useful tool for managing resources in multi-energy buildings
}

\author{
Benjamin Paris $^{1}$ Julien Eynard ${ }^{1}$ Michaël Salvador ${ }^{1}$ Stéphane Grieu ${ }^{1}$ \\ ${ }^{1}$ Laboratoire PROMES UPR CNRS 8521, Université de Perpignan Via Domitia, 52 av. Paul Alduy, 66860 Perpignan, \\ France ; benjamin.paris@ univ-perp.fr, julien.eynard@univ-perp.fr, grieu@univ-perp.fr
}

\begin{abstract}
The present paper focuses on using fuzzy logic as a useful tool to manage energy resources in buildings and to reduce their energy impact. To that purpose, one requires the design and the implementation of efficient and readily adaptable control schemes. As everyone knows, fuzzy logic allows taking advantage of the flexibility offered by linguistic reasoning. With this kind of approaches, both the specific use of a building and the specificities of a proposed energy management strategy can be easily considered when designing or adjusting the proposed control schemes. First, a hybrid PID-fuzzy scheme is used for managing resources in multi-energy buildings, as the combination of two usual control structures based on PID and fuzzy controllers: the "parallel" structure and the "fuzzy supervision" of a PID controller. Next, fuzzy logic is used to define scenarios dealing with building occupancy and to control the ventilation system of a building, with the aim of reducing its energy impact on the grid.
\end{abstract}

Keywords: energy performance of buildings, thermal comfort, hybrid PID-fuzzy scheme.

\section{Introduction}

Managing energy resources in buildings is fully related to both the development and the in-situ implementation of efficient control schemes. Controlling energy systems and/or actuators allows ensuring indoor comfort and, to a lesser extent, reducing energy consumption. Security and fault detection are also under consideration. Several tools, such as Multi Agent Control Systems (MACS) have already been developed with the aim of responding to the just-mentioned problematic [1]. Unfortunately, these tools are hard to develop and implement. Standard control schemes, such as "on/off" and $\mathrm{PID}$, are widely used in building engineering [2-6]. As an example, On/off controllers are used for indoor temperature regulation but, in this case, energy consumption is high because of both significant fluctuations and frequent set-point overshoots. This kind of control schemes perform poorly in some applications or environments (such as disturbed environments) and do not in general provide optimal control. PID controllers are feedback (or closed-loop) controllers with constant parameters and no direct knowledge of the considered process. When used alone, they usually give poor control performance for large time-delay process, in case of process noise or in the presence of non-linearities [7-8]. The present paper deals first with the development of an indoor temperature controller, allowing managing energy resources in buildings. The main objective of the proposed strategy is optimizing energy performance while ensuring thermal comfort, using the developed control scheme. One can highlight, and this is a key point, that we consider, in opposition of what one can find usually in the literature [1], buildings with both fossil and renewable energy resources (one can speak of "multi-energy" buildings) and we want the control scheme to be easily adaptable to different uses of buildings. A building mock-up has been built, instrumented and modeled to test the proposed controller in simulation. Instrumentation consists of height temperature sensors and two resistors used as heat sources. Finally, and because both the PMV [9] and the EPI [10] are hard to handle and only provide partial information, criteria describing the way energy is used and controlled in real-time have been defined with the aim of evaluating both the proposed energy management strategy and the hybrid control scheme performance. The first part of the present paper mainly focuses on the impact on these criteria and on energy consumption of both the fuzzification of the fuzzy controller's input and output parameters and the design of the rules. The second part of the paper deals with the development of building models using TRNSYS [11], a simulation software focusing on the transient performance of thermal energy systems, as well as on the use of fuzzy logic to develop an occupancy scenario and to control ventilation. The main goal of this part of the work is to reduce both the energy consumption and the energy impact on the grid.

\section{Energy resources management}

\subsection{Control criteria}

As just-mentioned, clear and easy-to-handle criteria are needed for evaluating the controller's performance. The proposed criteria allow evaluating thermal comfort, energy consumption and managing fossil and renewable energy resources in real time. First, the criterion $\%_{F E}$ is defined as the percentage of the fossil energy consumed $\left(E_{F E}\right)$ compared with the total energy used $\left(E_{T O T}\right)$. Let us note that energy is expressed in Wh.m ${ }^{-2}$. Then, the comfort criterion $I_{C}$, based on temperature set-point tracking, specifies the mean relative error between $T_{S P}$ $\left({ }^{\circ} \mathrm{C}\right)$ and $T_{m}\left({ }^{\circ} \mathrm{C}\right)$, with $T_{S P}$ the temperature set-point and $T_{m}$ the building's indoor mean temperature. Finally, the criterion $I_{P}$ focuses on both the performance of the proposed controller, comparing the two just-mentioned criteria, and the way the control scheme impacts energy consumption (3). As a key-point, one can highlight that 
the three proposed criteria allow adapting the proposed strategy, especially when designing the fuzzy rules, to the specific use of a building.

$$
\begin{gathered}
\%_{F E}=100 \times \frac{E_{F E}}{E_{T O T}} \\
I_{C}=100 \times\left(1-\frac{\left\|T_{S P}-T_{m}\right\|_{2}}{\left\|T_{S P}-<T_{S P}>\right\|_{2}}\right) \\
I_{P}=\left(I_{C}-\%_{F E}\right)
\end{gathered}
$$

Because both the use and occupancy of a building impact on temperature set-point profiles, specific temperature instructions (for offices and residential buildings respectively), recommended by the French "Règlementation Thermique 2005" [12], were used. This allows testing in several ways the robustness of the proposed hybrid control scheme.

\subsection{Design and modeling of a building mock-up}

Being able to instrument real buildings with a set of sensors for testing heating controller is rare. That is why a building mock-up has been built, instrumented and modeled. Instrumentation consists of height temperature sensors (one outdoor sensor and seven indoor sensors) and two resistors used as heat sources. The mock-up was built, taking as a reference a real one-floor building of $128 \mathrm{~m}^{2}$. Common building materials were used: gypsum plaster for walls, polyane for glasses (because of its low thickness) and polystyrene for insulation purposes. The study of the mock-up thermal behavior allowed proposing the model structure described by (4), with $T_{i}\left({ }^{\circ} \mathrm{C}\right)$ the indoor temperature measured by the $i^{\text {th }}$ sensor, $T_{\text {out }}\left({ }^{\circ} \mathrm{C}\right)$ the outdoor temperature, $k$ the time index (such as $t=k \cdot T_{e}$ and $T_{e}=60 \mathrm{~s}$ ), $u_{1}(\mathrm{~W})$ the power of the first heat source, $u_{2}$ (W) the power of the second heat source, $\alpha_{i}$ the inertia of temperature $T_{i}$, $\beta_{i 1}$ and $\rho_{i 1}$ two parameters characterizing the influence of the first heat source on temperature $T_{i}, \beta_{i 2}$ and $\rho_{i 2}$ two parameters characterizing the influence of the second heat source on temperature $T_{i}$ and, finally, $\gamma_{i}$ the influence of outdoor temperature on temperature $T_{i}$. Using an iterative process of error minimization depicted by $(5)\left(T_{\text {mes }}\left({ }^{\circ} \mathrm{C}\right)\right.$ and $T_{\text {mod }}\left({ }^{\circ} \mathrm{C}\right)$ are experimental and modeled temperatures respectively), all the parameters of Equation 2 are identified for each of the seven temperature sensors $(i=1, \ldots, 7)$ :

$$
\begin{gathered}
T_{i}(k+1)=\alpha_{i} T_{i}(k)+\beta_{i 1} u_{1}^{\rho_{i 1}}(k)+\beta_{i 2} u_{2}^{\rho_{i 2}}(k) \\
+\gamma_{i} T_{\text {out }}(k) \quad(4) \\
\min _{\alpha_{i}, \beta_{i 1}, \beta_{i 2}, \rho_{i 1}, \rho_{i 2}, \gamma_{i}}\left[J=\sum_{k=1}^{N}\left(T_{\text {mes }}(k)-T_{\text {mod }}(k)\right)^{2}\right]
\end{gathered}
$$

\subsection{Hybrid PID-fuzzy control scheme}

The present section of the paper deals with the design of the hybrid PID-fuzzy control scheme used for managing energy resources, ensuring thermal comfort and reducing energy consumption in multi-energy buildings. With the aim of both taking into account expert knowledge about the just-mentioned considerations and applying the proposed strategy to multi-energy buildings, a hybrid PID-fuzzy controller is proposed, as the combination of two usual control structures based on PID and fuzzy controllers: the "parallel" structure (according to the current dynamical state of the considered process, either the PID or the fuzzy controller is selected) and the "fuzzy supervision" of a PID controller [13]. Let us highlight that because PID controllers are commonly used in buildings engineering, the proposed control scheme is built on the basis of a PID controller. This allows implementing the scheme even if a control system based on such a controller is already in use and finding ways for improving its performance. The PID controller will be in charge of the main heat source $W_{R E}$ (the renewable energy warmer) while the fuzzy controller will both manage the secondary heat source $W_{F E}$ (the fossil energy warmer) and supervise the PID controller. Respective powers are about $80 \mathrm{~W}$ and $34 \mathrm{~W}$. Whatever the situation, $W_{R E}$ is used until power saturation is reached. Only at this point, $W_{F E}$ starts working. The hybrid PID-fuzzy control scheme proposed, which structure is described by Figure 1, allow easily taking into account the specific use of a building, thanks to the design of fuzzy rules [13]. From the difference between the set-point temperature $\left(T_{S P}\right)$ and the indoor mean temperature $\left(T_{m}\right)$, the PID controller estimates the power of $W_{R E}\left(U_{R E}^{P I D}\right)$ while a $1^{\text {st }}$ fuzzy module determines if this power needs to be corrected $\left(U_{R E}^{F L C}\right)$. From $\varepsilon$ and $U_{R E}=U_{R E}^{P I D}+U_{R E}^{F L C}$, a $2^{\text {nd }}$ fuzzy module evaluates the power of $W_{F E}\left(U_{F E}^{F L C}\right)$ :

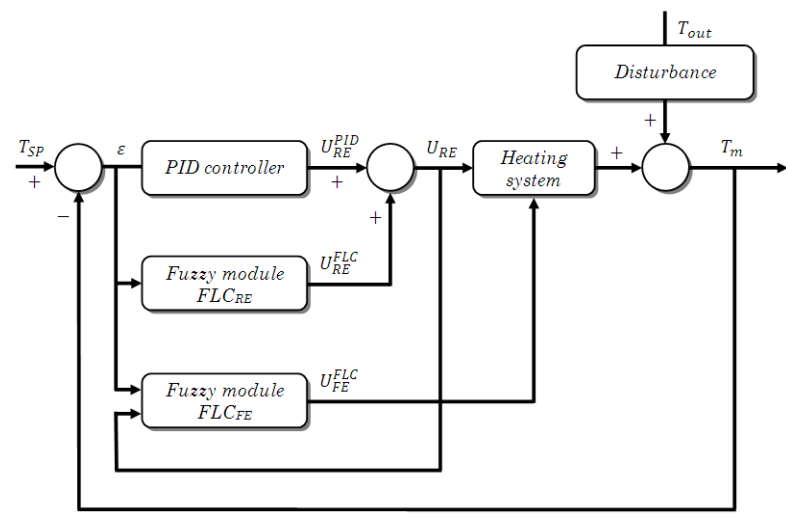

Fig.1: Hybrid PID-fuzzy control scheme.

The values of $U_{R E}^{F L C}$ and $U_{F E}^{F L C}$ are normalized between 1 and $+1\left(U_{R E}^{F L C} \in[-1 ;+1]\right)$ and 0 and $+1\left(U_{F E}^{F L C} \in\right.$ $[0 ;+1])$ respectively then denormalized using the gains $K_{R E}$ and $K_{F E}$. One needs, first, to characterize all the above-mentioned parameters and their respective "universes of discourse" using fuzzy sets and membership functions and, secondly, to define appropriate fuzzy rules that map inputs to outputs, with the aim of maximizing $I_{P}$ (thanks to the fuzzification process and the design of the fuzzy rules, one can easily take into account the specific use of a multi-energy building, favoring thermal comfort or minimizing the fossil energy 
consumption). (6) describes the way this indicator can be maximized, jointly optimizing all the controllers' gains $\left(K_{P}, K_{I}, K_{D}, K_{F E}\right.$ and $\left.K_{R E}\right)$, according to the system model:

$$
\max _{K_{P}, K_{I}, K_{D}, K_{R E}, K_{F E}}\left(I_{P}=I_{C}-\%_{F E}\right)
$$

\subsection{Results and discussion}

This section focuses on the results obtained about indoor temperature regulation when applying the proposed strategy, allowing managing energy resources in a multi-energy building, using both the mock-up model and the hybrid PID-fuzzy controller developed. The previously-mentioned criteria $\left(\%_{F E}, I_{C}\right.$ and $\left.I_{P}\right)$, describing the way energy is used and controlled in real-time, allow evaluating the performance of the control scheme and adapting to the specific use of a building. This section also deals with the impact on these criteria and on energy consumption of both the fuzzification of the fuzzy modules' input and output parameters and the design of the rule bases. Let us note that the performance of a PID control scheme with anti-windup system was considered as "reference" performance. From $\varepsilon=T_{S P}-$ $T_{m}$, this controller computes $U_{R E}^{P I D}$ and $U_{F E}^{P I D}$.

\subsubsection{Universes of discourse}

Let us remember that one needs, first, to characterize the fuzzy modules' input and output parameters and their "universes of discourse" using fuzzy sets, triangular or trapezoidal-shaped membership functions and linguistic labels and, secondly, to define appropriate fuzzy rules that map inputs to outputs, with the aim of implementing the proposed energy management strategy. Because of the thermal inertia, heat transfers between adjacent thermal zones and the heating system dimensioning, temperatures in buildings may be in the range $0^{\circ} \mathrm{C}-30^{\circ} \mathrm{C}$. Moreover, and according to the French "Règlementation thermique 2005", temperature set-points $\left(T_{S P}\right)$ may be in the range $7^{\circ} \mathrm{C}-22^{\circ} \mathrm{C}$. As a result, values for the difference between the set-point temperature and the (current) mean indoor temperature range between $-24^{\circ} \mathrm{C}$ and $+24^{\circ} \mathrm{C}\left(\varepsilon \in\left[-24^{\circ} \mathrm{C} ;+24^{\circ} \mathrm{C}\right]\right)$. As previously mentioned, the values of $U_{R E}^{F L C}$ and $U_{F E}^{F L C}$ are normalized between -1 and +1 and 0 and +1 respectively then denormalized using the gains $K_{R E}$ and $K_{F E}$. So, $U_{R E}^{F L C} \in[-1 ;+1]$ and $U_{F E}^{F L C} \in[0 ;+1]$. Finally, $U_{R E}$ being saturated at $80 \mathrm{~W}$, the universe of discourse of $U_{R E}$ is defined as follows: $U_{R E} \in[0 W ; 80 W]$. To be concise and because, whatever the set-point, similar results are obtained, only results for offices will be presented in the following sections of the paper.

\subsubsection{Impact of the fuzzification and the rules design}

Let us note that, because of measurement error due to the data acquisition tool used, control accuracy is \pm $0.5^{\circ} \mathrm{C}$. Usually, one considers that energy consumption increases by $7 \%$ over a year if the regulated indoor temperature rises above the set-point by $1{ }^{\circ} \mathrm{C}$. Both factors were considered during the fuzzification phase of the parameters. Let us also note that the control tool was designed without any consideration about control speed which is, however, a significant criterion in control engineering. Nevertheless, and with the aim of avoiding both the saturation of the renewable energy resource and set-point overflow, a progressive relaunch of the control process has been promoted. Tables 1 and 2 summarize all the significant results, obtained when using the hybrid PID-fuzzy control scheme for implementing the proposed energy management strategy, according to the fuzzification of the modules' input and output parameters and both the number and the design of the fuzzy rules. Nine configurations are proposed (from A to I). Both tables highlight how the justmentioned considerations are related with both the previously-defined criteria $I_{P}, I_{C}$ and $\%_{F E}$ and (fossil and renewable) energy consumption, when implementing the proposed control scheme in an office while taking into account its use and specific constraints. Increasing, from a starting configuration (A), the number of both the fuzzy sets (common triangular or trapezoidal membership functions and linguistic labels have been associated to the sets) used to split the respective universes of discourse of the modules' input and output parameters and the fuzzy rules led to the optimal configuration (E) which maximizes the performance criterion $\left(I_{P}\right)$. Let us also note, first, that the shape of the triangular membership functions used for characterizing $\boldsymbol{\varepsilon}$ around zero has been adjusted (the length of their respective bases has been reduced) from configuration $\mathrm{B}$ (this configuration allows minimizing $\%_{F E}$ ) to configuration $\mathrm{C}$ (this configuration leads to very good performance, rather close to the performance of the optimal configuration $\mathrm{E}$, but using less fuzzy rules) then from configuration D to configuration $\mathrm{E}$ (in this case, the number of fuzzy sets has also increased from 5 to 7), secondly, that the design of the fuzzy rules has been modified from configuration $\mathrm{E}$ to configuration $\mathrm{F}$ then from configuration $\mathrm{F}$ to configuration $\mathrm{G}$ and, finally, that the shape of the triangular membership functions used for characterizing $U_{R E}^{F L C}$ has been adjusted (the length of their respective bases has been extended) from configuration $\mathrm{H}$ to configuration $\mathrm{I}$.

\begin{tabular}{cccccccc}
\hline Config. & $\varepsilon$ & $U_{R E}^{F L C}$ & Rules & $\varepsilon$ & $U_{R E}$ & $U_{F E}^{F L C}$ & Rules \\
\hline$P I D$ & - & - & - & - & - & - & - \\
\hline$A$ & 3 & 3 & 3 & 3 & 2 & 3 & 6 \\
\hline$B$ & 5 & 5 & 5 & 5 & 2 & 5 & 10 \\
\hline$C$ & 5 & 5 & 5 & 5 & 2 & 5 & 10 \\
\hline$D$ & 5 & 5 & 5 & 5 & 2 & 3 & 10 \\
\hline$E$ & 7 & 5 & 7 & 7 & 2 & 5 & 14 \\
\hline$F$ & 7 & 5 & 7 & 7 & 2 & 5 & 14 \\
\hline$G$ & 7 & 5 & 7 & 7 & 2 & 5 & 14 \\
\hline$H$ & 7 & 5 & 7 & 7 & 2 & 4 & 14 \\
\hline$I$ & 7 & 5 & 7 & 7 & 2 & 4 & 14 \\
\hline
\end{tabular}

Table 1: Fuzzification and number of rules.

Taking a look at configurations A to I, one can first highlight the two following key-points: the difference between the set-point temperature and the current temperature (used as fuzzy modules input) has to be characterized by splitting its chosen universe of discourse into enough fuzzy sets, notably around zero, to obtain a 
good comfort criterion $\left(I_{C}\right)$ and to avoid oscillations of the controlled temperature around the set-point; splitting the universe of discourse of $U_{F E}^{F L C}$ into enough fuzzy sets allows limiting the use of fossil energy and improves consequently the criterion $\%_{F E}$. Both keypoints impact the performance criterion $\left(I_{P}\right)$ and define the way the hybrid PID-fuzzy scheme can be implemented according to the use of a building.

\begin{tabular}{cccccc}
\hline Config. & $\begin{array}{c}E_{R E} \\
{\left[W h . \mathrm{m}^{-2}\right]}\end{array}$ & $\begin{array}{c}E_{F E} \\
{\left[W h . \mathrm{m}^{-2}\right]}\end{array}$ & $\begin{array}{c}\%_{F E} \\
{[\%]}\end{array}$ & $\begin{array}{c}I_{C} \\
{[\%]}\end{array}$ & $\begin{array}{c}I_{P} \\
{[\%]}\end{array}$ \\
\hline$P I D$ & 7494.29 & 521.02 & 6.50 & 72.03 & 65.53 \\
\hline$A$ & 7236.19 & 473.99 & 6.15 & 59.69 & 53.54 \\
\hline$B$ & 7779.79 & 338.76 & 4.17 & 62.07 & 57.90 \\
\hline$C$ & 7504.92 & 480.95 & 6.02 & 72.14 & 66.12 \\
\hline$D$ & 7700.20 & 619.18 & 7.44 & 70.78 & 63.33 \\
\hline$E$ & 7731.35 & 470.66 & 5.74 & 72.38 & 66.64 \\
\hline$F$ & 7470.84 & 625.22 & 7.72 & 71.05 & 63.32 \\
\hline$G$ & 7426.40 & 654.02 & 8.09 & 71.08 & 62.98 \\
\hline$H$ & 7470.84 & 625.22 & 7.72 & 71.05 & 63.32 \\
\hline$I$ & 6709.86 & 760.13 & 10.20 & 69.48 & 59.31 \\
\hline & & & & &
\end{tabular}

Table 2: Consumptions and criteria.

\subsubsection{Optimal configuration E}

Taking as a reference the performance of the PID scheme, one can observe that the hybrid PID-fuzzy scheme, with optimal configuration $\mathrm{E}$, allows reducing the percentage of the fossil energy consumed compared with the total energy used by $11.7 \%$, from $6.50 \%$ to $5.74 \%$, and increasing both the comfort and the performance criteria by $0.5 \%$, from $72.03 \%$ to $72.38 \%$, and $1.7 \%$, from $65.53 \%$ to $66.64 \%$, respectively. Looking at Table 2, one can remark that configuration $\mathrm{E}$ provides the highest comfort criteria among all of the configurations we studied and that fossil energy consumption is significantly reduced while renewable energy consumption increases moderately: $E_{F E}$ is reduced by $9.7 \%$, from $521.02 \mathrm{Wh} . \mathrm{m}^{-2}$ to $470.66 \mathrm{Wh} . \mathrm{m}^{-2}$, while $E_{R E}$ is increased by $3.2 \%$, from 7494.29 Wh. $\mathrm{m}^{-2}$ to 7731.35 Wh. $\mathrm{m}^{-2}$. Similar results are obtained for houses.

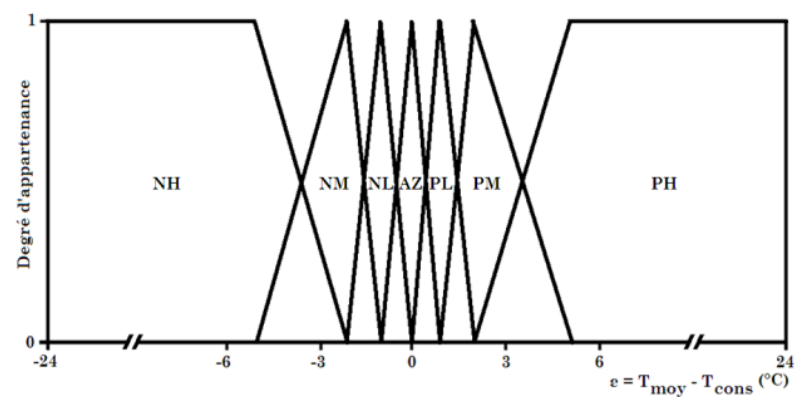

Fig. 2: Fuzzification of $\varepsilon$.

Figures 2, 3, 4 and 5 present the respective fuzzifications of $\varepsilon, U_{R E}, U_{R E}^{F L C}$ and $c$ while Tables 3 and 4 depict the two sets of fuzzy rules (modules $\mathrm{FLC}_{\mathrm{FE}}$ and $\mathrm{FLC}_{\mathrm{RE}}$ ), characterizing configuration $\mathrm{E}$. The following linguistic labels were associated to the fuzzy sets: NH (Negative High), NM (Negative Medium), NL (Negative Low), AZ (Approximately Zero), PL (Positive Low), PM (Positive Medium) and $\mathrm{PH}$ (Positive High) for $\varepsilon$, $U_{R E_{\_} \text {unsat }}$ and $U_{R E_{\_} s a t}$ for $U_{R E}, \mathrm{NH}$ (Negative High), NL
(Negative Low), AZ (Approximately Zero), PL (Positive Low) and $\mathrm{PH}$ (Positive High) for $U_{R E}^{F L C}$ and, finally, null, weak, medium, strong and full for $U_{F E}^{F L C}$.

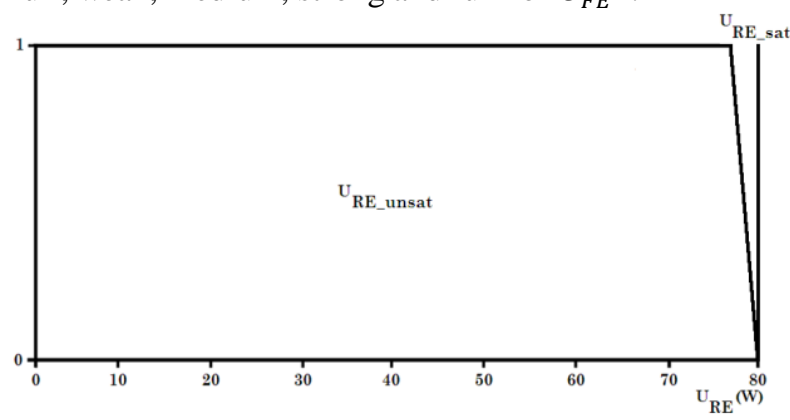

Fig. 3: Fuzzification of $U_{R E}$.

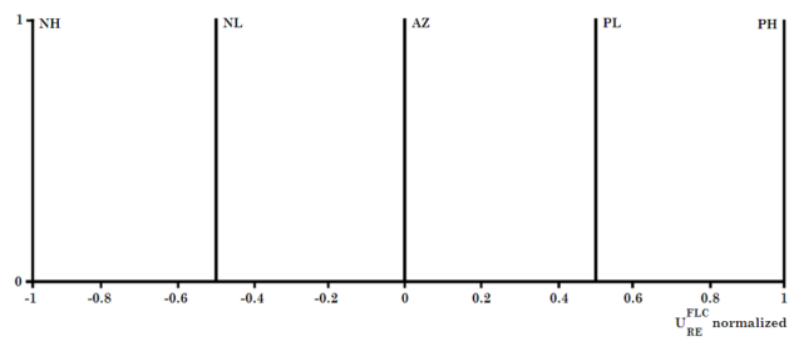

Fig. 4: Fuzzification of $U_{R E}^{F L C}$.

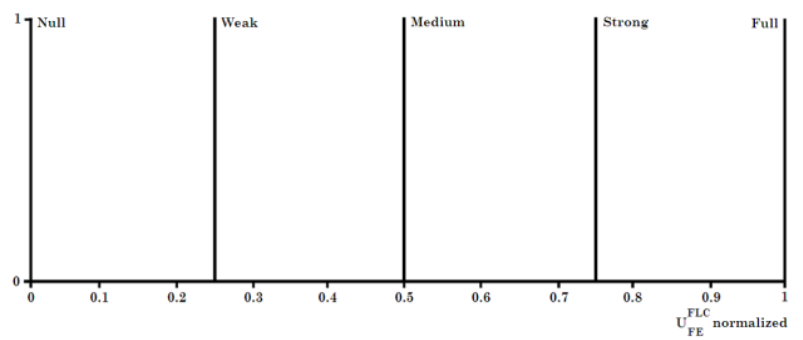

Fig. 5: Fuzzification of $U_{R E}^{F L C}$.

\begin{tabular}{cccccccc}
\hline Rule & 1 & 2 & 3 & 4 & 5 & 6 & 7 \\
\hline$\varepsilon$ & $N H$ & $N M$ & $N L$ & $A Z$ & $P L$ & $P M$ & $P H$ \\
\hline$U_{R E}^{F L C}$ & $N H$ & $N H$ & $N L$ & $A Z$ & $P L$ & $P L$ & $P H$ \\
\hline
\end{tabular}

Table 3: Fuzzy rules for module FLCRE.

\begin{tabular}{|c|c|c|c|c|c|}
\hline Rule & 1 & 2 & 3 & 4 & 5 \\
\hline$\varepsilon$ & $\mathrm{NH}$ & $N M$ & $N L$ & $A Z$ & $P L$ \\
\hline$U_{R E}$ & $U_{R E \_u n s a t}$ & $U_{R E \_ \text {unsat }}$ & $U_{R E \_ \text {unsat }}$ & $U_{R E \_ \text {unsat }}$ & $U_{R E \_u n s a t}$ \\
\hline$U_{F E}^{F L C}$ & Null & Null & Null & Null & Null \\
\hline Rule & 6 & 7 & 8 & 9 & 10 \\
\hline$\varepsilon$ & $P M$ & $P H$ & $\mathrm{NH}$ & $N M$ & $N L$ \\
\hline$U_{R E}$ & $U_{R E \_ \text {unsat }}$ & $U_{R E \_ \text {unsat }}$ & $U_{R E_{-} s a t}$ & $U_{R E_{s} s a t}$ & $U_{R E_{s} s a t}$ \\
\hline$U_{F E}^{F L C}$ & Null & Null & Null & Null & Null \\
\hline Rule & 11 & 12 & 13 & 14 & - \\
\hline$\varepsilon$ & $A Z$ & $P L$ & $P M$ & $P H$ & - \\
\hline$U_{R E}$ & $U_{R E_{s} s a t}$ & $U_{R E \_s a t}$ & $U_{R E \_s a t}$ & $U_{R E_{s} s a t}$ & - \\
\hline$U_{F E}^{F L C}$ & Weak & Medium & Strong & Full & - \\
\hline
\end{tabular}

Table 4: Fuzzy rules for module FLCFE.

\subsubsection{Temperature set-point tracking}

Using configuration E, set-point tracking is pretty good. The maximum deviation between $T_{m}$ and $T_{S P}$ is about 
$0.25^{\circ} \mathrm{C}$. The time response is about 30 minutes. However, taking a look at Figure 6, one can remark that during the 24-hour period, disturbances cannot be rejected completely (for example, at 10h30-11h). When the setpoint is $19^{\circ} \mathrm{C}$, only one significant overshoot (of about $1.3 \%$ ) can be noted, at $5 \mathrm{~h}$. If outdoor temperature decreases, indoor temperature is hard to stabilize and reaches the set-point with difficulty. When the set-point is $16^{\circ} \mathrm{C}$, variations and overshoots $\left(T_{m}\right.$ can exceed the set-point by up to $\left.1^{\circ} \mathrm{C}(6 \%)\right)$ are larger than when the set-point is $19^{\circ} \mathrm{C}$. However, indoor temperature stabilizes after about 15 minutes. At the end of the 24-hour period, when the set-point changes suddenly (from $19^{\circ} \mathrm{C}$ to $7^{\circ} \mathrm{C}$ ), both control quickness and the stabilization of $T_{m}$ are satisfactory. Using configuration $\mathrm{B}$, in particular when outdoor temperature is cold, $T_{m}$ oscillates with an amplitude of up to $1.3^{\circ} \mathrm{C}$. Although disturbances are well rejected, the controller lacks reactivity and precision. Indeed, when the set-point is $19^{\circ} \mathrm{C}$, the time response is about 30 minutes (which is relatively long). Overshoots are weak (about $0.2^{\circ} \mathrm{C}$ ) but one can note that $T_{m}$ doesn't reach the set-point temperature when outdoor temperature tends to decrease. Let us remember that because configuration $\mathrm{B}$ was designed with the aim of minimizing the percentage of the fossil energy consumed compared with the total energy used, one won't be surprised that thermal comfort is not optimal. As a consequence and whatever the hybrid controller configuration, implementing the proposed strategy for managing energy resources in buildings is a compromise between thermal comfort and energy consumption. When the set-point is $16^{\circ} \mathrm{C}, T_{m}$ both exhibits significant overshoots (up to $1.3^{\circ} \mathrm{C}$ ) and oscillates with a growing amplitude (from about $0.2^{\circ} \mathrm{C}$ to about $1^{\circ} \mathrm{C}$ ). At the end of the 24-hour period, when the set-point changes suddenly (from $19^{\circ} \mathrm{C}$ to $7^{\circ} \mathrm{C}$ ), $T_{m}$ continues to oscillate with an amplitude of about $1^{\circ} \mathrm{C}$.

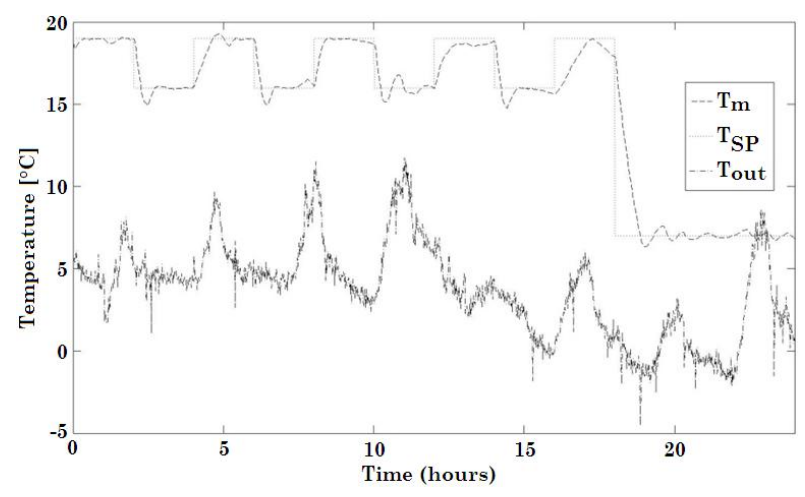

Fig. 6: Set-point tracking with configuration E.

Using configuration $\mathrm{C}$, one can note that the controller is precise during steady-state phases and pretty reactive during transitory phases. When the set-point is $19^{\circ} \mathrm{C}$, overshoots are weak (about $0.1^{\circ} \mathrm{C}$ ) and the time response is about 20 minutes. However, when outdoor temperature decreases, the time response increases to about $1 \mathrm{~h}$ and precision becomes bad. When the setpoint is $16^{\circ} \mathrm{C}$, precision is very good and the time response is roughly 15 minutes. $T_{m}$ oscillates with an amplitude of about $0.2^{\circ} \mathrm{C}$ and overshoots are weak (about $0.4^{\circ} \mathrm{C}$ ). At the end of the 24-hour period, when the setpoint changes suddenly (from $19^{\circ} \mathrm{C}$ to $7^{\circ} \mathrm{C}$ ), the time response increases up to about 40 minutes and $T_{m}$ oscillates with the same amplitude (about $0.2^{\circ} \mathrm{C}$ ).

\section{Energy impact and consumption minimization}

\subsection{Energy impact}

Usually, renewable energy production systems are designed to maximize the user financial benefits. Such systems can be used in buildings to meet a part (or the totality) of the energy demand. One speaks of "positive buildings". However, one can highlight that the amount of energy exchanged with the grid increases with time. A critical situation occurs when the amount of energy produced is close to the amount of energy consumed. Indeed, this leads to an increase of the frequency of exchanges. As a consequence, more and more electricity is carried through the grid, what causes large losses and threatens security. This section of the paper focuses on quantifying the energy impact of a building on the grid. First, we define, for a building connected to the grid, its real-time energy impact as the balance between its power demand $\left(W_{\text {dem }}\right)$ and the electric power it produces $\left(W_{\text {prod }}\right)(7) . n$ is the time index:

$$
E_{\text {impRT }}(n)=W_{\text {dem }}(n)-W_{\text {prod }}(n)
$$

Next, the energy impact of the building on the grid can be expressed by equation (8), with $W_{\max }$ the maximal value of the power demand (or the electric power produced and injected to the grid) during a time interval, $\mathrm{C}$ a coefficient to be fixed ( 3 is a good value) and $n_{u p}$ the upper limit of the study interval (time step is $1 \mathrm{~min}$ ):

$$
E_{\text {imp }}=\frac{\sum_{1}^{n_{\max }} e^{C \times \frac{\left|E_{\text {impRT }}(n)\right|}{W_{\max }}}-1}{n_{u p}}
$$

\subsection{TRNSYS model}

TRNSYS [11] and the SIMBAD toolbox for MATLAB [14] have been used to model the thermal behavior of typical residential buildings, offices and factories one can find across Europe. User profiles have been exploited to highlight the way energy is consumed. DAYSIM [15] allowed simulating artificial lighting. For the present work we considered only one building model, dealing with a $90 \mathrm{~m}^{2} 4^{\text {th }}$ floor flat in Perpignan (south of France), which orientation is south-west and inhabited by 4 people ( 2 adults and 2 children). Their lifestyle has been modeled. Solar thermal and photovoltaic panels, a vertical axis windmill as well as a hot water tank are considered.

\subsection{Occupancy scenario}

First, fuzzy logic is used to model the multi-energy building occupancy. The scenario we proposed allows managing the fatal heat production as well as electronic devices and household appliance. It is based on inhabitants' presence, meteorological data and traffic. Figure 
7 depicts the fuzzification of the inhabitants' presence. Gaussian membership functions were used. Such functions favor quick transitions. The following linguistic labels were associated to the five fuzzy sets: H (Holydays), W (Work), A (Away), J (Journey) and P (Present). "Work" is related to a standard working day while "Journey" means that the considered inhabitant is going from home to office (or school) or from office (or school) to home.

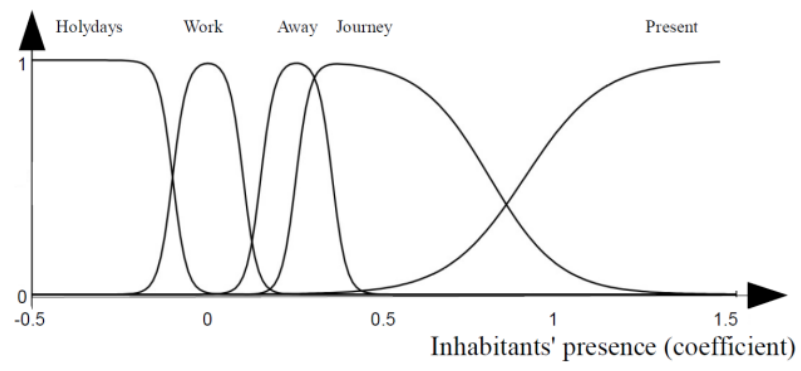

Fig. 7: Inhabitants' presence fuzzification.

Figure 8 shows the fuzzification of weather conditions. Triangular membership functions were used. According to outdoor temperature and rain, the following linguistic labels were associated to the three fuzzy sets: VB (Very bad), B (Bad) and G (Good). Figure 9 deals with the fuzzification of the Direct Normal Irradiance (DNI). Triangular and trapezoidal membership functions were used. N (Night) and D (Day) were associated to the two fuzzy sets we defined. Let us remember that direct normal irradiance is the amount of solar radiation received per unit area by a surface that is always help perpendicular to the rays that come in a straight line from the direction of the sun at its current position in the sky. We used the DNI only to differentiate day time from night time.

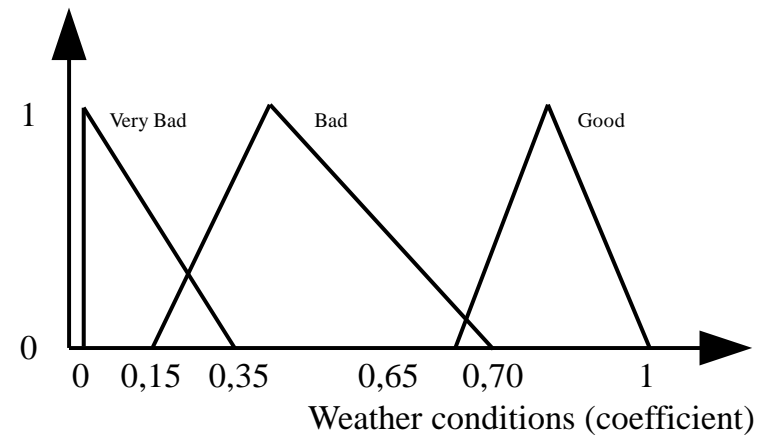

Fig. 8: Weather conditions fuzzification.

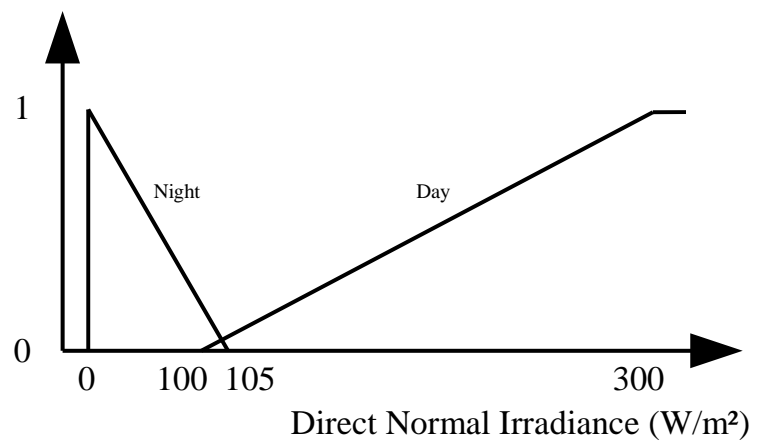

Fig. 9: Direct normal irradiance fuzzification.
Figure 10 depicts the fuzzification of traffic. Again, triangular membership functions were used. The following linguistic labels were associated to the two fuzzy sets: MF (Moving Freely) and S (Saturated). Knockingoff time is taken into account. Traffic, DNI and weather conditions are considered only to determine the away time.

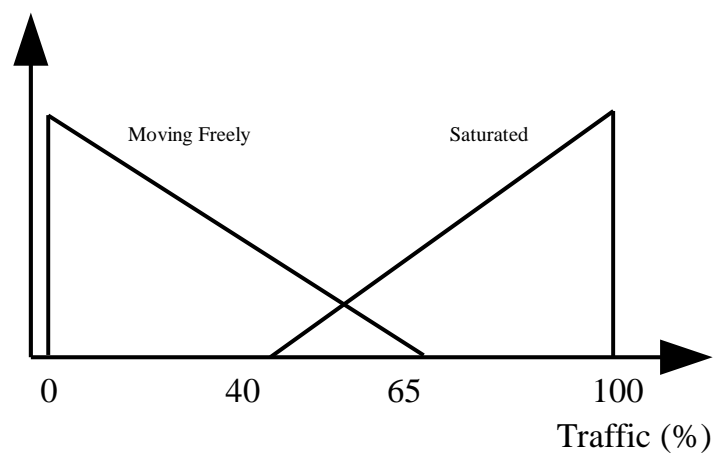

Fig. 10: Traffic fuzzification.

Figure 11 deals with the fuzzification of occupancy, for "day" (garage, laundry room, kitchen, dining room...) and "night" (bedrooms...) rooms. Because we want to reduce so far as we can computation time related to defuzzification (taken into consideration that the proposed tool will be implemented in real buildings to control their behavior in real-time), we used singletons as membership functions. The following linguistic labels were associated to the four fuzzy sets: A (Away), AL (Away Long), AS (Away Short) and P (Present).

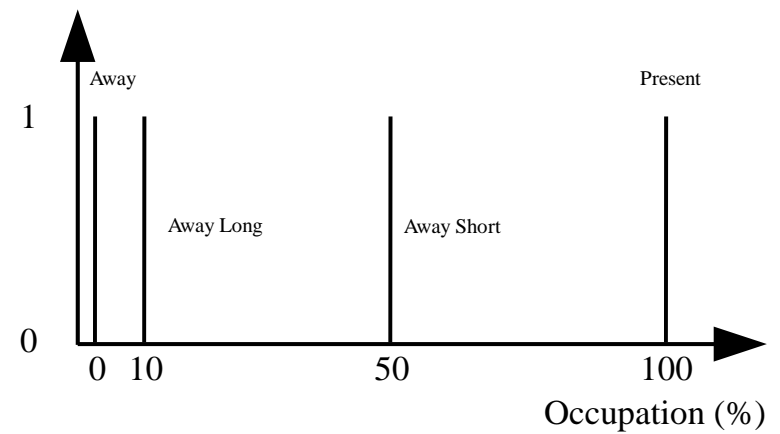

Fig. 11: Occupancy fuzzification ("day" and "night" rooms).

Finally, Table 5 depicts the design of the fuzzy rules (for a total of 19 rules). Each rule has two conclusions, the first one for "day" rooms and the second one for "night" rooms ("•" means "whatever the fuzzy set").

\subsection{Ventilation control}

Ventilation is a way to reduce energy consumption in buildings. The aim of ventilation is to exchange calories with outside and to favor inhabitants' thermal comfort. The fuzzy controller we propose has two inputs, indoor $\left(T_{\text {in }}\right)$ and outdoor $\left(T_{\text {out }}\right)$ temperature, and one output, the fan speed (FS). Indoor temperature is considered for each of the building rooms. We used triangular and trapezoidal membership functions for $T_{\text {in }}$ ( 6 fuzzy sets) and $T_{\text {out }}$ (5 fuzzy sets) as well as the following linguis- 
tic labels: Cd (Cold), Co (Cool), P (Pleasant), M (Mild), $\mathrm{H}$ (Hot) and VH (Very Hot) (Figures 12 and 13).

\begin{tabular}{cccccccc}
\hline Rule & 1 & 2 & 3 & 4 & 5 & 6 & 7 \\
\hline Presence & $J$ & $J$ & $J$ & $J$ & $J$ & $J$ & $J$ \\
\hline Weather & $V B$ & $B$ & $B$ & $G$ & $G$ & $V B$ & $B$ \\
\hline DNI & $D$ & $D$ & $D$ & $D$ & $D$ & $N$ & $N$ \\
\hline Traffic & $\bullet$ & $S$ & $M F$ & $S$ & $M F$ & $\bullet$ & $S$ \\
\hline Occ. (day) & $A L$ & $A L$ & $P$ & $A S$ & $P$ & $A L$ & $A L$ \\
\hline Occ. (night) & $A$ & $A$ & $A L$ & $A$ & $P$ & $A L$ & $A L$ \\
\hline Rule & 8 & 9 & 10 & 11 & 12 & 13 & 14 \\
\hline Presence & $J$ & $J$ & $J$ & $H$ & $W$ & $A$ & $A$ \\
\hline Weather & $B$ & $G$ & $G$ & $\bullet$ & $\bullet$ & $G$ & $G$ \\
\hline DNI & $N$ & $N$ & $N$ & $\bullet$ & $\bullet$ & $D$ & $N$ \\
\hline Traffic & $M F$ & $S$ & $M F$ & $\bullet$ & $\bullet$ & $\bullet$ & $\bullet$ \\
\hline Occ. (day) & $A L$ & $A L$ & $A S$ & $A$ & $A L$ & $A L$ & $A L$ \\
\hline Occ. (night) & $A S$ & $A S$ & $P$ & $A$ & $A L$ & $A L$ & $P$ \\
\hline Rule & 15 & 16 & 17 & 18 & 19 & - & - \\
\hline Presence & $A$ & $A$ & $A$ & $P$ & $P$ & - & - \\
\hline Weather & $B$ & $B$ & $V B$ & $\bullet$ & $\bullet$ & - & - \\
\hline DNI & $D$ & $N$ & $\bullet$ & $D$ & $N$ & - & - \\
\hline Traffic & $\bullet$ & $\bullet$ & $\bullet$ & $\bullet$ & $\bullet$ & - & - \\
\hline Occ. (day) & $A S$ & $A L$ & $A L$ & $P$ & $A L$ & - & - \\
\hline Occ. (night) & $A L$ & $A S$ & $A L$ & $A L$ & $P$ & - & - \\
\hline
\end{tabular}

Table 5: Fuzzy rules for occupancy.

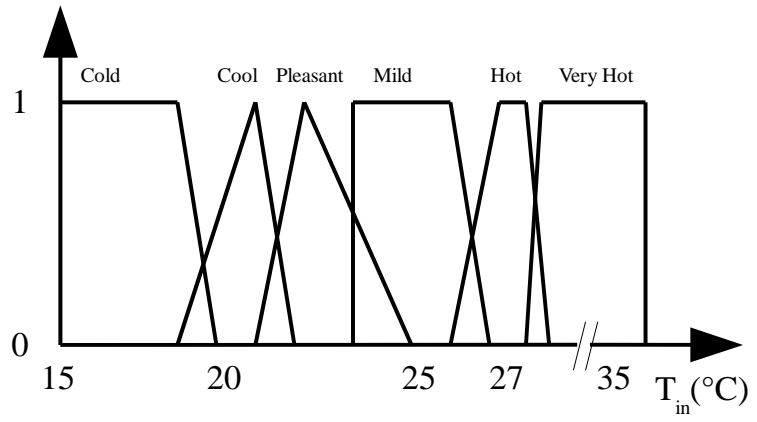

Fig. 12: Indoor temperature fuzzification.

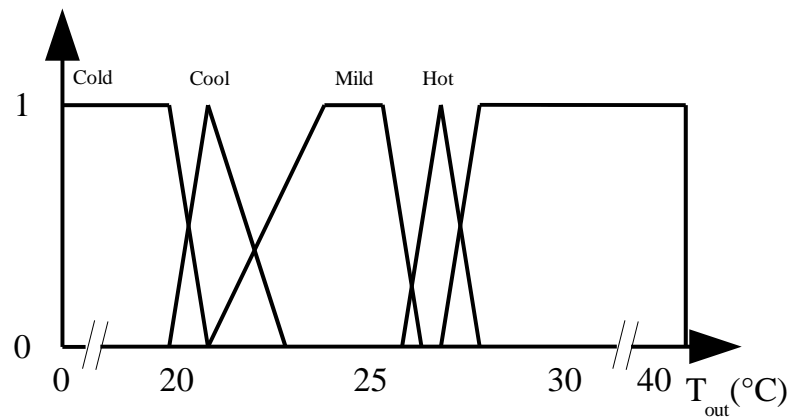

Fig. 13: Outdoor temperature fuzzification.

Let us note that, first, we defined only 3 fuzzy sets for $T_{\text {in }}$ and $T_{\text {out }}$ but the control results we obtained were disappointing. As a consequence, we increased to 5 the number of fuzzy sets used. This allowed the control strategy to be more subtle and flexible. Chaotic states were eliminated and the search for an optimal thermal comfort was more gradual. As a key point, one can note that we used a trapezoidal membership function for the fuzzy set "Hot" $\left(T_{i n}\right)$ because a triangular one leaded to instability. With an appropriate design of the fuzzy rules, this was eliminated. However, taking a look at indoor temperatures, we noticed that the temperature the controller was recommending in winter was too low, while, at times, outdoor temperature allows reaching a higher value and reducing energy consumption. That is why, after trying, unsuccessfully, to adapt the design of the fuzzy rules to solve the problem, we increased to 6 the number of fuzzy sets for $T_{i n}$, adding the fuzzy set "Pleasant". A triangular membership function was used. Finally, Figure 14 deals with the fuzzification of the fan speed. For the same reasons (related to computation time) as we did for occupancy (section 3.3), we used singletons as membership functions. The following linguistic labels were associated to the three fuzzy sets: S (Stop), S1 (Speed 1) and S2 (Speed 2).

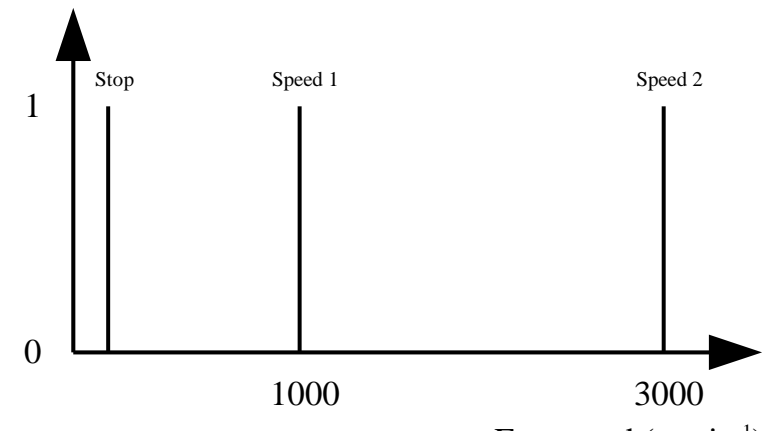

Fan speed (tr. $\left.\min ^{-1}\right)$

Fig. 14: Fan speed fuzzification.

Finally, Table 6 depicts the design of the fuzzy rules (for a total of 21 rules) used to control ventilation. As another key point, one can observe that some situations, dealing with exceptional weather conditions, are not correctly treated with the rules we designed. In this case, ventilation is stopped.

\begin{tabular}{cccccccc}
\hline Rule & 1 & 2 & 3 & 4 & 5 & 6 & 7 \\
\hline$T_{\text {in }}$ & $C d$ & $C d$ & $C o$ & $C o$ & $C o$ & $C o$ & $C o$ \\
\hline$T_{\text {out }}$ & $C o$ & $M$ & $C d$ & $C o$ & $M$ & $H$ & $V H$ \\
\hline$F S$ & $S$ & $S 2$ & $S$ & $S$ & $S 2$ & $S 1$ & $S$ \\
\hline Rule & 8 & 9 & 10 & 11 & 12 & 13 & 14 \\
\hline$T_{\text {in }}$ & $P$ & $P$ & $P$ & $P$ & $M$ & $M$ & $M$ \\
\hline$T_{\text {out }}$ & $C o$ & $M$ & $H$ & $V H$ & $C d$ & $C o$ & $M$ \\
\hline$F S$ & $S$ & $S 2$ & $S 1$ & $S$ & $S$ & $S 1$ & $S 2$ \\
\hline Rule & 15 & 16 & 17 & 18 & 19 & 20 & 21 \\
\hline$T_{\text {in }}$ & $M$ & $H$ & $H$ & $H$ & $V H$ & $V H$ & $V H$ \\
\hline$T_{\text {out }}$ & $H$ & $C o$ & $M$ & $H$ & $C o$ & $M$ & $H$ \\
\hline$F S$ & $S$ & $S 2$ & $S 1$ & $S$ & $S 2$ & $S 2$ & $S$ \\
\hline & & & & & & &
\end{tabular}

Table 6: Fuzzy rules for fan speed.

\subsection{Results}

Table 7 summarizes the results we obtained for a oneyear simulation (with and without occupancy scenario and ventilation control). The table deals with energy consumption, the energy performance diagnosis (DPE [10]), energy impact $\left(E_{\text {imp }}\right)$, the difference between the energy consumed and the energy produced and injected to the grid $\left(E_{b a l}\right)$ and, finally, the percentage of renewable energy produced and consumed in situ $\left(E_{A C}\right)$. Taking a look at Table 7 , one can highlight that both the occupancy scenario and the ventilation controller contribute to the reduction of energy consumption $(-8.2 \%)$, 
energy impact (-6.5\%), $E_{b a l}(-14.1 \%)$ and the DPE value $(-10 \%)$. Nevertheless, the percentage of renewable energy produced and consumed in situ is lower ($12.5 \%$ ) when using fuzzy logic.

\begin{tabular}{ccc}
\hline Parameter & $\begin{array}{c}\text { Without occupan- } \\
\text { cy scenario and } \\
\text { ventilation control }\end{array}$ & $\begin{array}{c}\text { With occupancy } \\
\text { scenario and ven- } \\
\text { tilation control }\end{array}$ \\
\hline $\begin{array}{c}\text { Energy consumption } \\
(\mathrm{kWh})\end{array}$ & 11000 & 10100 \\
\hline DPE $\left(\mathrm{kWh} \mathrm{m}^{2}\right.$. year $)$ & 90 & 81 \\
\hline$E_{\text {imp }}(-)$ & 3.1 & 2.9 \\
\hline$E_{b a l}(\mathrm{kWh})$ & 6400 & 5500 \\
\hline$E_{A C}(\%)$ & 24 & 18 \\
\hline
\end{tabular}

Table 7: Results.

\section{Conclusion}

This paper deals with the use of fuzzy logic to manage resources in multi-energy buildings. First, an indoor temperature control scheme, based on PID and fuzzy controllers has been developed. One speaks of "hybrid control scheme". A strategy for optimizing energy performance and ensuring thermal comfort, using the developed control scheme, has been proposed. Because PID controllers are commonly used in buildings engineering, this scheme has been built on the basis of a PID controller. Consequently, it can be implemented in buildings even if a control system based on such a controller is already in use. Thanks to the flexibility offered by fuzzy logic, the proposed hybrid control scheme allowed favoring one of the performance criteria we defined or adapting to the specific use of a building. Next, fuzzy logic has been used to develop an occupancy scenario and to control ventilation. The main goal of this part of the work was to reduce both the energy consumption and the energy impact on the grid.

\section{References}

[1] A.I. Dounis, C. Caraiscos, Advanced control systems engineering and comfort management in building environment-A review, Renewable and Sustainable Energy Reviews 13 (6-7) (2009) 12461261.

[2] C. Bernard, B. Guerrier, M.M. Rasset-Louerant, $O p$ timal building energy management. Part II: Control, ASME Journal of Solar Energy Engineering 114 (1982) 13-22.

[3] G.J. Levermore, Building energy management systems: an application to heating and control, E \& FN SPON, London, 1992.

[4] E.H. Mathews, D.C. Arndt, C.B. Piani, E. Heerden, Developing cost efficient control strategies to ensure optimal energy use and sufficient indoor comfort, Applied Energy 66 (2000) 135-159.

[5] I. Kaya, N. Tan, D.P. Atherton, Improved cascade control structure for enhanced performance, Journal Process Control 17 (1) (2007) 3-16.
[6] B. Thomas, M. Soleimani-Mohseni, P. Fahlen, Feedforward in temperature control in buildings, Energy and Buildings 37 (7) (2005) 755-761.

[7] K.H. Ang, G.C.Y. Chong, Y. Li, PID control system analysis, design, and technology, IEEE Transactions on Control Systems Technology 13 (4) (2005) 559-576.

[8] Y. Li, K.H. Ang, G.C.Y. Chong, PID control system analysis and design - Problems, remedies, and future directions, IEEE Control Systems Magazine 26 (1) (2006) 32-41.

[9] P.O. Fanger, Thermal comfort: analysis and applications in environmental engineering, McGrawHill, New York, USA, 1972.

[10] Official Journal of French Republic, Décret n²006-1147 du 14 septembre 2006 relatif au diagnostic de performance énergétique et à l'état de l'installation intérieure, 2006.

[11] TRNSYS The Transient Energy System Simulation Tool, www.trnsys.com.

[12] Official Journal of French Republic, Décret n²006-592 du 24 mai 2006 relatif aux caractéristiques thermiques et à la performance énergétique des constructions, 2006.

[13] R. Ketata, D. De Geest, A. Titli, Fuzzy controller: design, evaluation, parallel and hierarchical combination with a PID controller, Fuzzy Sets and Systems 71 (1995) 113-129.

[14] The SIMBAD toolbox, SIMBAD team, Centre Scientifique et Technique du Bâtiment (CSTB), http://kheops.champs.cstb.fr/Simbadhvac/index.htm 1.

[15] DAYSIM, http://www.daysim.com/index.html. 